\title{
Cuerpos, movilidades y espacios La calle recreativa de Rosario (Argentina)
}

\section{DIEGO ROLDÁN}

diegrol@hotmail.com - Centro de Estudios Culturales urbanos de Rosario (CECUR) /CONICET, Argentina

\section{SEBASTIÁNGODOY}

sebasgodoy13@gmail.com - Centro de Estudios Culturales urbanos de Rosario (CECUR) /CONICET, Argentina

Fecha de recepción: 19 de abril de 2017

Fecha de aceptación: 18 de mayo de 2017

\section{RESUMEN}

En las ciudades contemporáneas se implantan dispositivos para incentivar determinados repertorios de prácticas corporales y vectores de dirección. Este abanico de tecnologías de gobierno no actúa directamente sobre el cuerpo, sino que se despliega sobre las poblaciones como magnitud y el entorno urbano como ambiente. Seanalizaráeldesenvolvimiento de un dispositivo concreto, la Calle Recreativa de la ciudad de Rosario, que busca incentivar un tipo de movilidad específica (peatonal y con miras al esparcimiento y el ejercicio físico moderado), empleando ciertas arterias de la ciudad como circuito y al espacio público como escenografía. A través de la adecuación de un medioespecífico yartificial,laCalle encauza un abanico de prácticas de la población, mientras que consigue animar los espacios públicos urbanos más valorizados del mercado inmobiliario, que funcionan para los peatones como un paisaje puesto al servicio de la recreación, y promover la imagen turística y el diseño global de la ciudad. Para entender su funcionamiento, se ha realizado un trabajo de campo de tipo cualitativo consistente en observaciones sumadas al registro dela experiencia del propio cuerpo de los investigadores en el uso de la calle.

palabras Clave: Cuerpos, ciudad, espacio público, recreación, motricidad.

\section{ABSTRACT}

In contemporary cities, the implementation certain types of devices is increasingly common, which, far from curtailing the mobility of their populations, incentivize certain repertories of body practices and direction vectors. This range of government technologies does not act directly upon individual bodies, but unfolds upon populations as a magnitude and urban environment as an ambient. In this paper, the development of a particular device will be analyzed, the Recreational Street en Rosario city, which seeks to promote a specific type of mobility (a pedestrian one, with the aim of recreation and moderate physical exercise), using certain arteries of the city as a circuit and the public space as scenery. Through the adaptation of a specific and artificial environment, the street funnels a range of practices of the population while powers the most valued urban public spaces. They function as a landscape for pedestrians in the service of the recreation, and promote the tourism image and overall design of the city. To understand its performance, a field work has been carried out which consist in qualitative observations added to the record of the experience of the body of researchers in the use of the street.

KEY WORDS: Bodies, city, public space, recreation, $k i$ netics. 


\title{
ENTRE CUERPOS YESPACIOS
}

\begin{abstract}
“Trabajaba cuando el espíritu le impulsaba a ello (generalmente de noche) y el resto del tiempo vagabundeaba libremente, deambulando por las calles de la ciudad como un flâneur del siglo XIX, dejándose guiar por su instinto. Paseaba, iba a museos y galerías de arte, veía películas a cualquier hora del día, leía libros en los bancos del parque. No estaba sometido al reloj como lo están otras personas. En consecuencia, nunca tenía la sensación de estar perdiendo el tiempo. Eso no significa que no fuese productivo, pero el muro que separa el trabajo y el ocio se había desmoronado para él hasta tal punto que apenas se daba cuenta de su existencia."
\end{abstract}

Paul Auster (1993)

No hace tanto tiempo que el cuerpo se constituyó en un problema para las ciencias sociales. Actualmente, gran parte de las investigaciones sobre este tópico se inscribe en los campos de la sociología (Turner, 1989) y la antropología (LeBreton, 1995). No resulta sorprendente, entonces, que Marcel Mauss (1936) estuviera entre los primeros en proponer ese objeto analítico. El estudio sobre las técnicas corporales constituyó el primer intento sistemático de reflexionar sobre cuerpo como una construcción social sometida a variaciones culturales. Esas técnicas configuran hábitos corporales (caminar, yacer, emitir sonidos y otras) que, antes de que Mauss amalgamara cuerpo y cultura, habían sido pensados como hechos puramente biológicos.

Hacia mediados del siglo XX, las ciencias sociales comenzaron a preocuparse más sistemáticamente por el cuerpo (Leenhardt, 1947 \& Hall, 1959). A partir de los trabajos de Mary Douglas (1970) y Victor Turner (1969), se configuró el campo específico de la antropología del cuerpo. En Símbolos naturales, Douglas planteó que lo orgánico espeja a lo social y viceversa. Sin embargo, durante esas décadas el cuerpo distó de ser estudiado exclusivamente por antropólogos y sociólogos. La filosofía, a través de la fenomenología, retomó la indagación sobre el tema, tras el largo impasse de la hegemonía cartesiana, tan solo interrumpida por las problematizaciones spinozianas sobre el cuerpo ylas críticas nietzscheanas a las escisiones cuerpo-mente.

Fenomenología de la percepción de Maurice Merleau-Ponty (1945) construyó una propuesta compleja alrededor de la corporalidad, convirtiéndose en un claro referente para los estudios posteriores. En su planteo, el cuerpo, como forma de habitar el mundo, constituye una modalidad de conocimiento diferenciada del cogito cartesiano. El mundo corporalmente percibido estructurala matriz experiencial de la que se deriva todo el andamiaje racional y científico. El filósofo francés opone el ser-en-el-mundo al sujeto de conocimiento. Elcuerpo se entrama con el mundo y con otros cuerpos, es tanto una mediación como un "espacio expresivo", un "medio general de poseer un mundo", pero "sin subordinarse a una 'función simbólica’ u 'objetivante”' (Merlau-Ponty, 1993, pp. 161, 163 y 158). Sobre las huellas dejadas por Merleau-Ponty y con conceptos 
procedentes de diversas tradiciones filosóficas: Blasile Pascal, Erwing Panofsky y el estructuralismo, Pierre Bourdieu (1999) desarrolló su concepto de habitus y su idea del conocimiento por cuerpos. Esa teoría tuvo una aplicación ejemplar en la etnografía del boxeo realzada en Chicago por Loïc Wacquant (2004).

Hacia finales del siglo XX, cierta literatura académica mencionaba la producción de un giro corporal y el nacimiento de los corporal studies (Sheets-Johnstone, 2009), refiriéndose a la multiplicación de las reflexiones que pusieron el acento en el cuerpo. Aparecen, entonces, nuevas perspectivas como la del embodiment (Csordas, 1993, 1999); que propone dejar de pensar lo corporal como objeto de estudio y comenzar a entenderlo, al mismo tiempo, como sujeto, como sustrato existencial que configura lo cultural y lo subjetivo. Para Csordas, la conciencia es cuerpo, retomando la lectura merleau-pontyana y su anti-cartesianismo.

A pesar de este marcado y reciente interés sobre el cuerpo, las propuestas analíticas que intentan trazar puentes y cruces entre el cuerpo y el espacio han quedado menos desarrolladas (Low, 2003a). Quizá esta falta de contacto se deba a que el abordaje sobre la cuestión espacial tampoco fuera tan profundo. $\mathrm{Al}$ igual que la corporalidad, el espacio quedó relegado a un segundo plano en el campo de las ciencias sociales y confinado al ámbito de los estudios geográficos. De hecho, el concepto de espacio por mucho tiempo en las ciencias sociales quedó atrapado en las redes de una serie de operaciones analógicas pre-reflexivas. Desdela primera modernidad, el espacio fue delimitado y sobre todo organizado por el discurso jurisdiccionalista del derecho y las formas de poder político bajo la noción de territorio político y jurisdicción administrativa (Hespanha, 1989). Posteriormente, en el siglo XIX, fue constreñido por el discurso de la naciente biología. Allí, darwinismo mediante, fue identificado con el territorio del Estado, asimilado a un recurso vital y disputable (lebensraum) en una especie de ecología-política (Farinelli, 2000). Durante el período de entre siglos, con el desgaste del positivismo y la aparición del neokantismo y ciertas vertientes del historicismo (Gregory, 1978), el espacio fue pensado como paisaje humanizado, cuya homogeneidad-unidad delineaba las regiones naturales de la geografía humana francesa (Lacoste, 1977).

En la entreguerras, las regiones y los paisajes naturales fueron impactados por el problema de la cultura material, estimulada por la geografía cultural de base antropológica con epicentro en la Escuela de Berkeley. Fragmentos de estas tendencias se entrelazaron con algunas vertientes dela economía alemana no marxista, para dar nacimiento a la llamada geohistoria (Ribeiro, 2015). En la década del ' 60 del siglo pasado, con el neopositivismo y la aparición de la new geography, el espacio fue sometido a un riguroso proceso de abstracción y concebido como un conjunto de coordenadas que distribuían nodos y flujos en una red isomorfa e isotrópica (Crampton \& Kryeger, 2006). Ese espacio abstracto, inicialmente plasmado en las teorías de la localización de las actividades 
económicas, constituyó el plano ideal para la colonización de la geografía por la economía liberal y neoliberal (Cosgrove, 2004). Algunas de estas tendencias fueron redistribuidasy destiladas, a través de una nueva fórmula de economía y sociología histórica a gran escala inscripta en las especulaciones circulacionistas de Inmanuel Wallersten (2006) que alumbraron el muy utilizado concepto de sistema-mundo. Estos derroteros, en los que la reflexión espacial aparece alternativamente vinculada y/o dependiente de la política, la biología, la historia y la economía han comenzado a desplazarse recientemente, a partir de los desarrollos de la geografía crítica, post-estructuralista (Gregory, 1996) y, especialmente, de su reflexión concentrada sobre el espacio urbano (Smith, 1990, 2013; Harvey, 1990, 2007, 2008; Soja 1989, 1996, 2000).

En el campo de las ciencias sociales, casi paralelamente, se ha comenzado a plantear un giro corporal y otro espacial (Soja, 2010). Sin embargo, ambas tendencias han permanecido más o menos desconectadas. Aun compartiendo una matriz post-estructuralista estas dos relecturas del cuerpo y el espacio aparecen separadas debido a la ausencia de un diálogo más intenso entre las disciplinas que se han abocado al estudio de cada una de ellas: la antropología del cuerpo yla geografía del espacio. Esa desvinculación se torna algo inestable, por ejemplo, al reflexionar sobre el concepto de espacio social, más allá dela teoría delos campos de Pierre Bourdieu. Desde esta perspectiva, el espacio aparece tramado por relaciones sociales que, en definitiva, están soportadas e inscriptas en los cuerpos.

Por otra parte, el cuerpo es el soporte material y simbólico, último y primario, de toda la interacción social (Roldán, 2010). A partir de él, de sus multiplicidades e interrelaciones se hilvanan las sociedades como configuraciones de sentido variables, magmáticas y siempre en estado de emergencia. El cuerpo es, además, elvehículo indispensable para la generación de percepciones, que, a su vez, son el insumo principal de los imaginarios y las culturas. A fin de cuentas, sin el cuerpo no existiría la imaginación espacial, formada a partir de diferentes modos de autopercepción y de percepción de o los otros.

Uno de los conceptos clave para intentar articular estas dos categorías de cuerpo y espacio es el de movilidades. El crecientemente voluminoso y veloz desplazamiento delos cuerpos, los objetos yla información a través de distintas redes ha dado lugar a la construcción de un paradigma de la movilidad. Este punto de vista se ha articulado con las tecnologías del transporte, la información y lo que John Urry (2004) denominó la mirada del turista.

El concepto de "movilidades" incluye tanto los movimientos en gran escala de gente, objetos, capital e información a través del mundo, como los procesos más locales de transporte diario, movimiento a través del espacio público y de objetos materiales en la vida cotidiana (Hannam et al., 2006, p. 1)

A diferencia delas posiciones de Augé (1998) sobrelos nolugares, consideramos que tanto el arraigo y la permanencia como el movimiento constituyen 
dos modalidades de apropiación del espacio. Además de los patrones de arraigo, los de movimiento colectivo construyen las condiciones de producción y apropiación del lugar.

Precisamente, nos proponemos analizar la movilidad de los cuerpos en un espacio público urbano específico. Procuramos estudiar las relaciones de los usuarios de un dispositivo de movilidad generado desde el gobierno municipal que transforma las vías vehiculares (automotrices) en extendidas sendas peatonales. Nos interesa reconstruir las formas de producción y apropiación de la Calle Recreativa de la ciudad de Rosario en tanto espacio de solapamiento y/o encuentro de un régimen de movilidad y de una práctica del movimiento ${ }^{1}$. Indagamos cómo sus usuarios emplean sus cuerpos en movimiento dentro de lo que se entiende, al mismo tiempo, como un dispositivo de movilidad y parte de una tecnología de gobierno que actúa creando un medio. La Calle Recreativa es un espacio perimetrado e intervenido por la administración municipal. Esas operaciones producen un medio artificial donde el movimiento aparece libre de todo tipo de ataduras, cuando en realidad está condicionado en su propia producción, organización y sentido.

La hipótesis que orienta este trabajo es que la Calle Recreativa utiliza y expresa, a través de la adecuación de un medio específico y artificial, el deseo de esparcimiento y actividad física moderada de una población. Por otra parte, su diseño incentiva un repertorio de prácticas que giran en torno a la idea de "recreación", entendida como una forma de movimiento distendida, laxa y capaz de "oxigenar" a los cuerpos agotados o atrofiados por las actividades laborales semanales de un capitalismo postindustrial, en general sedentarias. Con el argumento de lograr esta oxigenación, este circuito consigue animar los espacios públicos urbanos más valorizados del mercado inmobiliario, que funcionan para los peatones como un paisaje puesto al servicio dela recreación, y promover el imaginario turístico-saludable y de competitividad global de la ciudad (Vera, 2015a).

La producción de datos necesarios para lograr esos objetivos proviene de una estrategia de dos caras. Por un lado, el insumo fundamental utilizado fue la observación centrada en ciertos caracteres dela Calle Recreativay sus usuarios, mediante un trabajo de detección y registro. Por otro, los propios cuerpos de los investigadores fueron empleados para recorrer la Calle, en una modalidad de "observación participante". Detectando los usos que los cuerpos en movimiento hacen de la Calle y empleando el propio cuerpo para experimentar lo que produce esa modalidad y sus formas específicas de motricidad, se configuró una grilla hermenéutica de doble entrada que permitió aprehender la configuración de la Calle en tanto dispositivo de circulación y medio para el gobierno de las poblaciones. El trabajo de campo fue realizado durante un

1 Un circuito temporal donde se suspende el tránsito automotor para el uso exclusivo de medios de locomoción no motorizados o "recreativos", como bicicletas, rollers, skates o las mismas piernas de los transeúntes. 
período de ocho meses, a través de una observación con participación. Los registros resultantes de estas operaciones fueron complementados con una serie de procedimientos interpretativos que permitieron aproximarnos a las formas de funcionamiento del circuito y su desenvolvimiento.

\section{EL ESPACIO PÚBLICO COMO DISPOSITIVO URBANÍSTICO}

Con frecuencia, los discursos de la planificación urbana articulan el binomio “espacio público". Desde mediados de la década de 1980, el espacio público alcanzó gran proyección en las gestioneslocales delas ciudades que se imaginan competitivas, atractivas y capaces de posicionarse en los rankings internacionales (Borja \& Muxi, 2003). Al mismo tiempo que la planificación estratégica local y regional ganó terreno, la ciudad fue, cada vez más, el teatro de las operaciones de los diseñadores y los promotores inmobiliarios. El espacio público, como imaginario y materialidad, se ha convertido hoy en día en un dispositivo urbanístico central que contiene, al menos, un doble propósito. Mientras que su producción y proliferación es una de las modalidades en que los gobiernos locales consiguen articular los diseños públicos con la inversión privada, también, permite elevar la plusvalía de los suelos loteables y construibles, aledaños a estas intervenciones.

En paralelo, el discurso oficial sostiene que el espacio público es una especie de islote de igualdad, un pequeño paraíso natural yocioso, emergente en medio del tumultuoso mar urbano dela desigualdad, la alienación y la contaminación. Es continuamente referenciado como un espacio colectivo, accesible y visible a todos los ciudadanos (Rabotnikof, 1996). Este campo discursivo, producido como una forma de gubernamentalidad, en el sentido quele atribuye al término Michel Foucault $(2006 \mathrm{~b})^{2}$, proyecta la imagen del espacio público como la de un dique, un muro de contención, frente al avance desenfrenado del neoliberalismo urbano y de la privatización de la ciudad. Más allá del cambio de imagen de la ciudad y la accesibilidad de un espacio público de calidad a la ciudadanía, el proceso de construcción de los nuevos espacios públicos del frente ribereño (riverfront), como dispositivos urbanísticos generadores de valor inmobiliario y de legitimidad política, es uno de los puntos donde se intersecan las fuerzas de los capitales privados y los intereses públicos.

Se trata, entonces, de un espacio de colaboración intensa entre la administración y las empresas, una alianza estratégica en la que se configura el corazón del mercado inmobiliario, pero también de un ámbito de traducción fuerte de

2 El concepto de gubernamentalidad foucaultiano es la tercera de la secuencia de las relaciones de poder que elabora Foucault (2006a, pp. 15-44) en la clase del 11 de enero de 1978 de Seguridad Territorio y Población. La gubernamentalidad se apoya en el discurso del liberalismo y el neoliberalismo, creando un ambiente artificial y actuando sobre la población que lo habita. Sila soberanía se basaba en la coerción exterior y se aplica al territorio, la disciplina en la coacción interiorizada en el cuerpo dócil, la gubernamentalidad se apoya en una suerte de persuasión del sujeto, a través del gobierno del deseo, procurando su autorregulación no por coacción o disciplinamiento, sino a través de la inducción de su más íntima convicción. 
esa sinergia a los términos de un proceso de inclusión y participación social. Es precisamente esa ambivalencia la que hace del espacio público un fenómeno que oscila entre su imaginario y materialidad. Ese imaginario ha sido diseñado para lacrar la inclusión y el acceso de los habitantes y para promover el turismo entre los que visitan ocasionalmente la ciudad.

A partir de las transformaciones urbanísticas y las operaciones simbólicas de la planificación y el marketing, se forjan imágenes y escenografías que privilegian la estética por encima de la función, capaces de poner en valor ciertas partes de la ciudad en detrimento de otras. La mayoría de esos sectores están vinculados a la maximización del espacio urbano como experiencia de consumo y mercancía turística. En general, los espacios turísticos y renovados, las postales de la ciudad posmoderna, también, son las que se utilizan para publicitar prácticas saludables. Como lo ha demostrado Paula Vera (2015a), la ciudad turística y la ciudad saludable dentro del imaginario del marketing y la competitividad interurbana ingresan en una especie de circuito de retroalimentación. Algunos municipios como el de Rosario plantean completar su imagen con la idea de ser un municipio saludable. Esta figura retórica forma parte de la planificación estratégica y enfatiza las ideas de calidad de vida, accesibilidad y promoción de la salud.

Con el objetivo de encaminar las conductas de los sujetos hacia el campo de lo saludable, se producen una serie de modificaciones en el medio. En principio, se destacan las características que hacen de la ciudad un lugar especial para el desarrollo de estas actividades: bajos niveles relativos de contaminación, amplia línea de costa, importantes recursos naturales, espacios públicos, parques y paseos debidamente equipados y con capacidad para albergar una multiplicidad de actividades (Plan Estratégico Rosario Metropolitana2010, p.212).Sin embargo, los dones naturales son necesarios, pero no suficientes. La cultura de la calidad de vida necesita de la construcción de espacialidades urbanas que contribuyan a fortalecer los hábitos asociados con el culto a la salud y el bienestar. En el PERM 2010, aparece la idea de una infraestructura del movimiento. Especialmente adoptada en los espacios verdes ylos de circulación. Las infraestructuras del movimiento promueven los hábitos saludables y la convivencia armoniosa. La Calle Recreativa es una de esas infraestructuras eventuales que plantea la producción de un entorno de convivencia, encuentro, esparcimiento, vida saludable y actividad física recreativa para todos los ciudadanos.

Con una extensión total de 28 kilómetros, la Calle Recreativa propone incentivar ciertos hábitos saludables y, casi en paralelo, fomentar una recuperación del espacio público a partir de la convivencia ciudadana y el ocio masivo (participativo). Uno de los medios de locomoción más usados en la Calle es la bicicleta, en gran parte, promovida por el mismo municipio. Con la construcción de una infraestructura de 105 kilómetros de ciclovías, la administración local ha apoyado esta iniciativa que consiste en reducir el uso del 
automóvil. Partiendo de las experiencias de Masa Crítica, procedentes de San Francisco y replicadas alrededor del planeta (Hou, 2010), la administración local ha conseguido que el Banco Interamericano de Desarrollo reconociera a Rosario como la ciudad de Latinoamérica en la que se produce el mayor uso de las bicicletas.

Figura 1. Plano oficial. Vía Recreativa Rosario

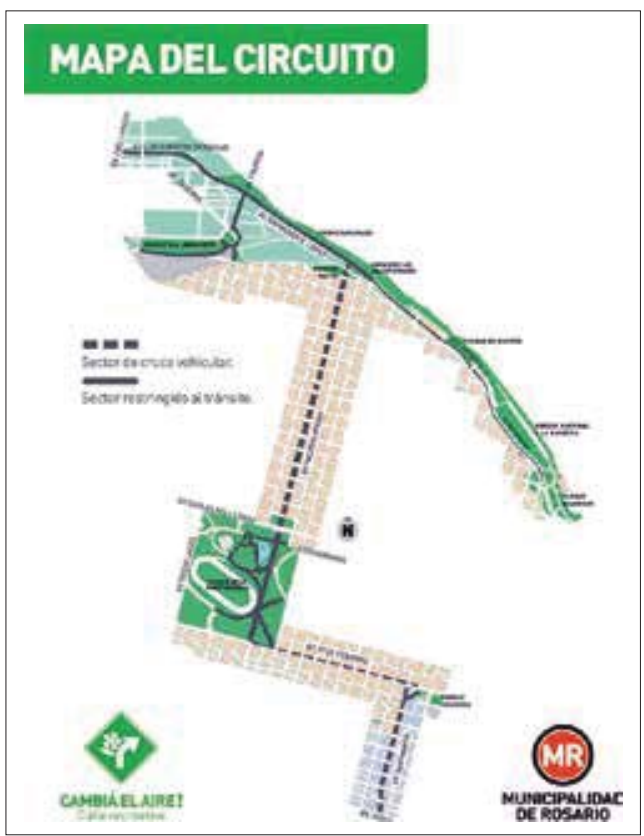

Fuente: Municipalidad de Rosario.

\section{MERODEANDO EN LA CALLE RECREATIVA}

\section{La movilidad y sus medios}

Los domingos por la mañana (entre las 8 y las 13 horas), tres de las principales avenidas de la ciudad de Rosario son retiradas del imperio del tráfico automotor para dibujar en la trama una figura zigzagueante, aunque dominada por la rectitud de los ángulos del damero. Esta concatenación de perpendicularidades sólo se trastoca al chocar con la costa central del río Paraná: allí, la arteria eventualmente exceptuada de motores adquiere caracteres más curvos y continuos, imitando la silueta de la ciudad que linda con el curso de agua. Curiosamente, cuando la Calle Recreativa se evade del dominio de la traza, el paseante ingresa en un mundo urbano distinto, signado por la presencia de 
emprendimientos inmobiliarios privados de alta gama, que emergen como menhires a un lado de la llanura del espacio verde rosarino.

Quienes transitan por esta calle cuentan con sus corporalidades como fuente del movimiento: en esta área acotada y rectilínea de la ciudad, las formas de motricidad - aunquevariadas - son impulsadas por factores bióticos y niegan con cierta contundencia los medios de transporte basados en el combustible fósil. De hecho, la única forma de ingresar con un automóvil en esa zona restringida es para cargar gasolina, en algunas de las estaciones de servicio que se encuentran localizadas dentro del recorrido. Allí, unos conos anaranjados, alejados de la univocidad sígnica, señalan la posibilidad de que por cien metros y con una finalidad precisa los autos puedan aparecer en el paso de otros vehículos. Los seres humanos y su kinesis básica —el caminar- son amplificados por un repertorio de dispositivos mecánicos cuya movilidad recae también en el esfuerzo muscular. A lo largo del paseo, la bicicleta es el medio hegemónico. Hay una mayor proporción de bicicletas particulares, pero también aparecen las que provienen del sistema de bicicletas públicas de la Municipalidad de Rosario "Mi Bici, Tu Bici". El tipo de bicicleta particular muestra una variedad de modelos. Sin embargo, predominan las de paseo y las inglesas, muchas de estas últimas refaccionadas y pintadas siguiendo la estética y la gama de colores del estilo vintage. Gran parte de estos ciclistas llega al circuito en pequeños grupos con lazos familiares o de amistad. Otra modalidad de movilidad frecuente es la caminata, muchas personas emprenden el trayecto de la Calle Recreativa para poder caminar sobre la cinta asfáltica, destinada durante el resto de la semana al paso de los automóviles. En general, este flujo peatonal exhibe un ritmo relajado, acompasado por conversaciones que se efectúan en grupos de por lo menos dos personas. Aunque los hay, son notablemente menos frecuentes los caminantes solitarios. Algunos paseantes realizan los trayectos en familia o con sus mascotas. Una proporción menor de quienes recorren la Calle lo hace en una modalidad de trote, aunque sin grandes explosiones de velocidad ni la intensidad características de un entrenamiento riguroso que no puede detenerse. También hay quienes utilizan otro tipo de medios de movilidad con ruedas como los rollers y en menor medida las patinetas o longboards.

\section{Un ritmo para la recreación y la oxigenación}

Aunque mayormente relajado, el ritmo de la circulación es permanente y constante. Salvo cuando el tráfico de las calles perpendiculares - no comprometidas con el circuito- lo demanda, casi nadie se detiene. Al tener que aguardar el cruce de automóviles en las bocacalles de la Calle Recreativa, los que están haciendo algún tipo de ejercitación rítmica detienen por completo la marcha y esperan al cambio de semáforo o, en los casos donde no hay uno, a que el inspector de tránsito los habilite a pasar. En este sentido, parece más o menos claro que la actividad física rigurosa está subordinada a un movi- 
miento principalmente recreativo que parece ser la pieza más importante en el juego de ese circuito especial. Otra razón para un detenimiento eventual de los transeúntes es, ante el mutuo reconocimiento, el saludo y el intercambio de algunas palabras.

De esta manera, la constancia y la permanencia del ritmo de avance no implican su explosividad. La cadencia observada en el andar fue más bien leve, con una intensidad que solo se presenta en el largo plazo y en el avance de la posición, en una especie de búsqueda, aún parcial, de completar ciertas fases del recorrido. Ese ritmo parece evidenciar antes un descanso en movimiento que un apronte al entrenamiento físico. La Calle Recreativa parece imponerse como un momento de descanso y distensión para aquellos que entrenan regularmente en la semana y la utilizan el domingo para realizar algún tipo de ejercicio aeróbico al aire libre y de baja intensidad. De igual manera, otra población de hábitos y trabajos quizá más sedentarios se pone en movimiento, tratando de dar con una forma para descansar de su quietud e inmovilidad laborales. Las rutinas son alteradas tanto por el fin de semana que pone límites a las tareas regulares como por la Calle Recreativa que coloca al cuerpo en una cinta imaginaria de movimientos tan leves como constantes. Las mañanas de domingo en la Calle Recreativa parecen ajustarse al oxímoron de la necesidad del descanso en movimiento, propio de la fluidez y la flexibilidad de la época.

Por otra parte, el slogan municipal "Cambiá el Aire” se aproxima con buen criterio a algunas de las motivaciones de quienes utilizan este paseo. Más que una frase que apunta a la cuestión de la respiración y el ejercicio físico, indica una relación con el cambio de hábitos y la discontinuidad con las rutinas. Se pasa de cierto sedentarismo o de una actividad que persigue algún resultado o rendimiento específico a una circulación que no tiene motivos exteriores a sí misma. Un movimiento que se produce a partir del placer que genera el propio movimiento, una especie de perpetuum mobile sin objetivos ni finalidades. Aunque no queda claro si es una proyección gubernamental afincada exitosamente en los transeúntes o una inquietud de la población adoptada por los mentores del circuito, la idea de oxigenación aparece en como un universo compartido entre unos y otros. Desde los carteles colocados a lo largo del recorrido que instan a "cambiar de aire" hasta las formas de motricidad distendidas y de "afloje", esa idea y su manifestación corporal se unifican en los distintos tramos de la Calle. También se han colocado, en ciertos puntos estratégicos, distintas estaciones en el recorrido. Allí se practican ejercicios ritmados por diferentes musicalidades (salsa, cumbia y reggaetón), se dan masajes gratuitos, se realizan ejercicios de yoga, relajación y otros. A esto se añade un taller de bicicletas a cielo abierto y gratuito, la ocasional publicidad de algún producto que se reparte en forma, también, gratuita, con lo que el municipio no solo busca sponsorear el recorrido, sino también incentivar la atracción que ejerce y la animación que reviste el paseo. 


\section{Cuerpos posicionados y vestidos}

Dependiendo del medio de locomoción escogido, la actividad de circulación se despliega en sincronía, los ritmos en general tienden a acompasarse, los desacoples se expresan en pequeños grupos o individuos aislados. Esos diferenciales son posibles cuando la Calle no está completa y el flujo es menos compacto, sobre todo en las primeras horas de la mañana. Hacia el mediodía la Calle consigue aglutinar su máxima concurrencia. En algunos tramos, los cuerpos aparecen en una proximidad muy notable. Muchos casi se rozan. Comparten el espacio, pero también el tempo del movimiento. Despliegan una marcha en multitud y en cierta compañía anónima, aun sin conocerse forman parte de un flujo y un impulso similares. Esa especie de danza coordinada en una proximidad que no llega a ser contacto parece basarse en algún tipo de convenio o pacto tácito entre los caminantes, ciclistas y patinadores que comparten el espacio y los ritmos-movimientos. Para quien se desplaza por la Calle a cierta velocidad, no existe forma de anticipar cuándo y a qué distancia puede sobrepasarlo otra persona que avance a un ritmo mayor. La única manera de evitar posibles colisiones termina siendola rectitud del patrón de avance: como si se tratase de andariveles imaginarios, los vectores de trayectoria se mantienen paralelos a los cordones de las veredas de la calle. El movimiento se amolda a los indicadores de dirección y trayectoria del medio que lo enmarca.

Como bien lo subrayó Goffman (1993), la vestimenta es un código sintético de información social. La mayor parte de quienes atraviesan la Calle Recreativa lo hacen muñidos de ropa funcional, en general del tipo deportivo. Sin embargo, esa hegemonía delo funcional no hace desaparecer las elecciones y montajes estéticos. Estas estrategias se ofrecen reforzadas en algunos casos que combinan tonalidades, aun en gamas estridentes propias de la ropa deportiva. Ese tipo de régimen vestimentario exhibe la naturaleza del vínculo que tienen los paseantes con la actividad que se desarrolla en y fuera delárea, particularmente su involucramiento con cierto entrenamiento físico quizá riguroso. Una forma de movilidad que en la Calle Recreativa es difícil de ejercer, pero que quizá precisamente por eso pueda convocarse como un complemento dela identidad a través de la semiosis del vestuario (Entwistle, 2002). Al mismo tiempo, estos rituales de la ocupación del espacio público también permiten una visibilidad casi total, con miles de puntos de observación parciales, pero de una desmultiplicación exponencial. Los cuerpos en movimiento significan para los transeúntes la forma de expresarse y aprehender las expresiones de otros, un medio para percibir y ser percibidos (Merleau-Ponty, 1945). Los contactos visuales probablemente sean la forma más poderosa de comunicación e interacción de estos usos del espacio público limitados por estas configuraciones eventuales. En los rituales de exhibición, el cuerpo se constituye, al mismo tiempo, en una coordenada material y simbólica. La vestimenta, en tanto conjunto de signos identificable por los otros, funciona como un operador de distinción que reve- 
la una posición social y una presumible dedicación relativamente rigurosa al ejercicio que se solapa con la posición espacial que mantienen los caminantes y el escenario-medio que los envuelve.

\section{Clasificando a los usuarios}

Los diversos grupos que se movilizan a través de la Calle Recreativa cubren un amplio espectro etario que va desde los niños acompañados de sus padres hasta los adultos mayores. Todos recorren el trayecto según sus necesidades y posibilidades. Aunque existe una predominancia de jóvenes y de adultos, la variedad de edades es muy notable. Menos marcada es la diversidad de posición social. Las capas medias son predominantes en todos los tramos de la Calle. Esa hegemonía apenas es matizada por una presencia muy moderada, momentánea y, la mayor parte de las veces, discreta de los sectores populares. En ocasiones, la aparición delos sectores populares plantea una discontinuidad en el flujo. Una ruptura que es certificada por la mirada que le dedican el resto de quienes circulan en la Calle. Esas miradas parecen ponerlos en el lugar de un objeto extraño, de algo llegado de un lugar desconocido, que perturba un flujo homogéneo e incapaz de absorberlos. Menos disruptiva es la presencia de grupos pertenecientes a las zonas superiores del espacio social que se acoplan al flujo aeróbico especialmente en la parte centro norte del recorrido, cuando el recorrido se hace paralelo al río Paraná. De igual forma, existe una homogeneidad étnica también bastante caracterizada. Casi todos los usuarios de la Calle Recreativa son de tez blanca, hay muy pocos que ofrecen las marcas de la migración interna y latinoamericana que caracterizó y caracteriza a una buena porción de las poblaciones ubicadas en la periferias informales de las principales ciudades argentinas.

Sibien la propuesta dela Calle Recreativa, parcialmente, plantea la posibilidad de realizar una especie de recorrido turístico saludable en la propia ciudad, noparecegenerar efectos demasiado importantes entrela población que habita las periferias. Posiblemente, esto obedezca a una especie de zoning estipulado por el recorrido, donde quedan excluidas una gran porción de la zona sur y la totalidad de la zona oeste de la ciudad. Ambas áreas constituyen los mayores contenedores de población de extracciones populares. Allí todavía se encuentran activas las infraestructuras ferroviarias, en cuyos terrenos históricamente se han instalado los asentamientos irregulares. También puede observarse la consolidación de la composición de la clase media en la medida en que el recorrido se prolonga hacia el norte. Recientemente, esa área ha sido recuperada de sus usos ferro-portuarios por los capitales privados. Allí se asienta una población de alto poder adquisitivo y status social, formada por profesionales y empresarios. Hacia Puerto Norte, un barrio de distribución poligonal y con importantes indicadores de aislamiento del resto de la traza urbana, la ciudad signada por su famosa ronda de bulevares queda completamente cancelada: 
el predominio absoluto es el de las comunidades cerradas sobre sí mismas, con una fuerte impronta heterotópica (Foucault, 2010), en tanto funcionan al margen, albergando conjuntos de población específicos, fomentando prácticas determinadas por reglas precisas y perimetrando sus límites con barreras físicas al resto del tejido urbano (Low, 2003b).

Con respecto a las identidades de género, es difícil hacer un análisis detallado, cuando el principal insumo son los datos construidos a partir de la observación de cuerpos en movimiento. De todas maneras, se puede efectuar una apreciación empírica de las performáticas generizadas que se observaron. En primer lugar, la familia hétero-patriarcal domina la escena. Cuando los transeúntes constituyen grupos de más de dos personas, la composición predominante cuenta con dos adultos - varón y mujer - y uno o más niños, vestidos con los típicos atuendos y colores asignados a los roles masculinos y femeninos, respectivamente. Es menos frecuente encontrar mujeres en el recorrido que no revistan los caracteres vestimentarios deportivos asignados a lo femenino. Asimismo, las mujeres son las mayores usuarias de rollers y patines dentro del circuito, estando en paridad con su contraparte masculina en el empleo de bicicletas. Mientras que muchos varones transitan solos o en grupos familiares, el agrupamiento femenino es mediante parejas, tanto del mismo como de distinto género. En ese andar, la interacción sólo se produce con el o la acompañante. A medida que el recorrido se aproxima al norte y cambia el paisaje urbano, los grupos de mujeres crecen en cantidad, en detrimento de las familias. En esta parte "más exclusiva" del escenario de la Calle, la zona recostada sobre la ribera central y norte es donde aparecen algunas parejas (mujer-mujer y varónvarón). No obstante, el espacio de la calle recreativa no parece ser un lugar para mostrar disidencias o alternativas respecto a los modelos familiares, las posiciones sociales y los roles de género hegemónicos. Es ante todo un espacio para la escenificación y, por lo tanto, la reproducción-afirmación ritual-práctica de un orden social preexistente y hegemónico. Solo en fragmentos y fisuras pudo observarse la contestación a ese orden donde los imaginarios de "la salud y el bienestar corporal" se integran a los de la "seguridad y la salud social".

\section{Dirección y espacios}

Mientras que la avenida 27 de Febrero - el límite distrital que separa al sur del centro- solo habilitó una de sus sendas para el uso de la Calle Recreativa, en el tramo San Martín (sur) y en los de Bulevard Oroño y de Puerto Norte, el recorrido suspende ambas sendas para el uso automotor y reproduce la doble orientación del tráfico para el uso mayoritario de los caminantes y ciclistas. Sin embargo, la mayor parte del trayecto está diseñada con un fuerte sentido sur-norte. Gran parte del flujo asume como propia esa dirección y describe el trayecto buscando dos cuestiones que parecen remarcables: la zona septentrional de la ciudad, con el renovado sector de Puerto Norte como escenario de 
pujanza urbana y la ribera del Paraná como escenografía natural. Quizá esos sean los dos motivos más importantes que consiguen imprimirle una direccionalidad tan clara al flujo humano que atraviesa el circuito. La orientación impresa desde la planificación de la Calle es adoptada por los usuarios, quienes asumen el eje sur-norte como el recorrido natural a seguir como un flujo del que es imposible evadirse o en el que no es sencillo crear atajos. De este modo, la calle Recreativa se transforma en una calle de dirección única, abierta por un ingeniero en el corazón de la ciudad.

En lo que se refiere a las vías de conectividad, los recorridos están pautados a través de cuatro avenidas que en cierta medida delimitan, también, cuatro áreas de la ciudad. El primer tramo es el de mayor penetración meridional: La Av. San Martín desde su intersección con Bulevar. Seguí hastala segunda arteria del recorrido, Av. 27 de Febrero. Este segmento avanza sobre una zona comercial, de una de las calles más representativas y multifuncionales de Rosario, que se reparte entre concesionarias de autos e iglesias de diversas confesiones. Al tomar la avenida 27 de Febrero, la Calle solamente habilita la circulación peatonal para el carril con dirección al norte, una clara indicación acerca de la dirección del flujo. A un costado de este trayecto aparece, algo difusa, la parte noroeste del parque Yrigoyen: la plaza Lucio Fontana, con su Monumento al Che Guevara y las inmediaciones de la Estación del Ferrocarril Central Córdoba, cuya rehabilitación, aún muy relativa, ofrece una anticipo empobrecido de lo que le espera en el otro extremo de la Calle con las instalaciones de Puerto Norte. La zona de 27 de Febrero presenta un entorno con predominancia de las construcciones residenciales, salpicadas por algunoslocales comerciales. El recorrido también tiene habilitado un solo carril de la avenida para la circulación peatonal con dirección hacia el Oeste. En sus últimos trescientos metros, emerge el borde de la silueta del Parque Independencia que, junto al bulevar Oroño, articula la siguiente fase.

Al llegar a la convergencia de 27 de Febrero y Oroño la concurrencia aumenta, la cinta asfáltica está a completa disposición de los paseantes, los automóviles no pueden ingresar en absoluto, ninguna dirección está habilitada en esta fase de la Calle para ellos. Los paseantes pueden moverse tanto con sentido sur-norte como norte-sur, pero la direccionalidad del paseo para los que lo han iniciado antes ya es un asunto decidido.

A un lado, del principio de esta fase del recorrido con rumbo norte, el antiguo predio de la Sociedad Rural de Rosario y al otro, el predio del desmantelado parque de diversiones mecánicas. En esta zona la vegetación es escasa y la marcha se vuelve poco confortable frente a los rayos solares. Al llegar al Rosedal y el antiguo Hipódromo del Jockey Club de Rosario las ramas más altas de las dos hileras de tilos plantadas a los costados del bulevar se entrelazan formando un techo verde sobre la cinta asfáltica. En las inmediaciones del Museo de la Ciudad aparecen un sitio para realizar ejercicios de relajación, un 
puesto de reparación de bicicletas, un gazebo donde se venden vasos con jugo de naranjas y otro donde unas colchonetas indican que puede hacerse ejercicio de piso. Finalmente en un espacio cuadrangular se ofrece un "Taller aeróbico de ritmos" organizado por el Municipio. Allí, sobre un pequeño escenario, un profesor guía los movimientos corporales de los participantes, que siguen la música emitida por unos parlantes laterales. El parque concluye en el cruce de Oroño y Pellegrini. Allí comienza la fase más céntrica del recorrido. Esta parte del trayecto se despliega sobre uno de los vértices de la primera ronda de bulevares (el equivalente al casco histórico de otras ciudades latinoamericanas). El bulevar Oroño y sus mansiones de fines del siglo XIX y comienzos del XX son los escenarios escogidos para ambientar la circulación. Se trata de la antigua zona residencial, exclusiva y de figuración social de la élite local. El último tramo del recorrido pone en diálogo las áreas del bulevar céntrico y la que colinda con el recientemente rehabilitado-gentrificado barrio de Pichincha, sede de un circuito gastronómico bastante exclusivo, donde, por ejemplo, el transporte público tiene una llegada difusa e infrecuente.

La recta de Oroño choca con el Parque Norte y el Scalabrini Ortiz, allí emerge la silueta del Paraná y el trayecto comienza a seguir la curva de la ribera para retener la vista, aunque a cierta distancia, de las aguas del río. El área que comienza a recorrerse se caracteriza por cierta discontinuidad. Existen sectores que mantienen un mobiliario urbano y unas instalaciones algo modestas, allí las cintas asfálticas no existen o son precarias, la única vegetación está formada por algunosárboles pequeñosy el césped es cortado regularmente, pero sin otra pretensión que mantenerlo en un largo aceptable para un paseo público. Por otra parte, el terreno no se encuentra nivelado con rigurosidad y son frecuentes los cambios de altura y las discontinuidades de la cubierta verde. Además, en la zona se presentan hitos de acondicionamiento todos promovidos por la inserción del capital privado en el espacio público. Las zonas adyacentes a los bares Río Mío y los Silos Davis, inmediatos al Museo de Arte Contemporáneo de Rosario (MACRO), presentan ajardinamientos especiales, una infraestructura y un mobiliario urbano de alta calidad que contrasta con otras partes del recorrido. La discontinuidad vuelve a emerger al traspasar el MACRO, construido a partir de la recuperación de la estructura de un elevador de granos que data de comienzos de la década del '30 del siglo pasado. La playa de maniobras del Nuevo Central Argentino sobre el costado sur exhibe instalaciones y ruinas del pasado ferro-portuario de la ciudad. Mientras que al otro lado, la costanera, libre de galpones y construcciones que afecten la perspectiva, es recuperada por intervenciones públicas que no se destacan por esa estética minimalista y esa vegetación extremadamente cuidada y especialmente escogida que emerge de los espacios intervenidos por el capital privado. Todo el recorrido por la Avenida Estanislao López y luego por la Cándido Carvallo muestra los ensayos e intervenciones sobre la ribera rosarina en pos de la construcción de un water- 
front, donde se rehabilitan los residuos de la ciudad portuaria y se los convierte en espacios refuncionalizados para ponerlos a prestar servicios y funciones en el marco de una escenografía turística y post-ferroportuaria. La postal de la ribera alcanza quizá su máximo esplendor en el trayecto que se extiende entre las torres Dolfines y Ciudad Ribera. La perspectiva del río y las nuevas construcciones de edificios inteligentes para oficinas y residencias muestran una diversidad y una escala que pone en cuestión su relación con el resto de la trama urbana. Al parecer, el espacio público aparece aquí como una especie de interface o membrana capaz de absorber el efecto que ocasiona esa zona de excepción que conforman estos complejos de vivienda de altísima gama. De igual manera, el residuo portuario es reabsorbido por funciones hoteleras o de ventas de servicios.

En su direccionalidad y linealidad, todo el recorrido configura una narración que cuenta algunas cosas, mientras silencia otras. La propuesta paisajística y espacial de la Calle Recreativa muestra selectivamente una Rosario que pretende seducir a los usuarios del recorrido. El circuito resalta partes de la ciudad en detrimento de otras. Excluye áreas que componen hitos importantes de su historia y su morfología, pero que posiblemente estén asociadas a un localismo nostálgico que se quiere suprimir a favor de identificadores más acordes a un imaginario cosmopolita, internacional y "turistificable" (Vera, 2015b). Lo que se desea mostrar es la perspectiva de una primera modernidad urbana, caracterizada por cierto afrancesamiento de los petit hotels ylas mansiones del Bulevar Oroño, así como una "segunda modernidad" o post-modernidad globalizadora, signada por las nuevas construcciones en altura y los emprendimientos recualificadores del espacio público. Lugares como el Parque de la Bandera -otrora un espacio simbólico de suma importancia en el casco central-y el prácticamente intransitable microcentro de la ciudad se suman a los barrios del sur y el oeste en la lista de los olvidados del paseo. Ese perfil urbano que combina algunos paseos burgueses de fines del siglo XIX y principios del XX, más las nuevas zonas recualificadas para las nuevas élites del siglo XXI, aspira a ser leído a partir de cualquier retícula cultural occidental; también aspira a ser interpretado universalmente, sin sentidos situados. Intenta dejar atrás las señas locales que siempre caracterizaron y en algunos relatos empobrecieron a Rosario frente al puerto cosmopolita de Buenos Aires. En otras palabras, la Calle Recreativa configura a la ciudad como un producto aprovechable para cualquier consumidor del mundo, sin necesidad de mediaciones ni traducciones. Además, hace dela ciudad una mercancía consumible en tanto experiencia universalista y apta para todo aquel que quiera y pueda permitirse pagarla. Porque si bien el circuito es "gratuito", puede ser pensado como una ammenity agregada a los costos de habitar y visitar la ciudad. Una ammenity que junto al paisaje ribereño incrementa exponencialmentelos valores del metro cuadrado del suelo en las zonas más renovadas-gentrificadas de Rosario. 
Figura 2. Estación de ejercicios y ritmos. Parque de la Independencia (Bv. Oroño y Pellegrini)

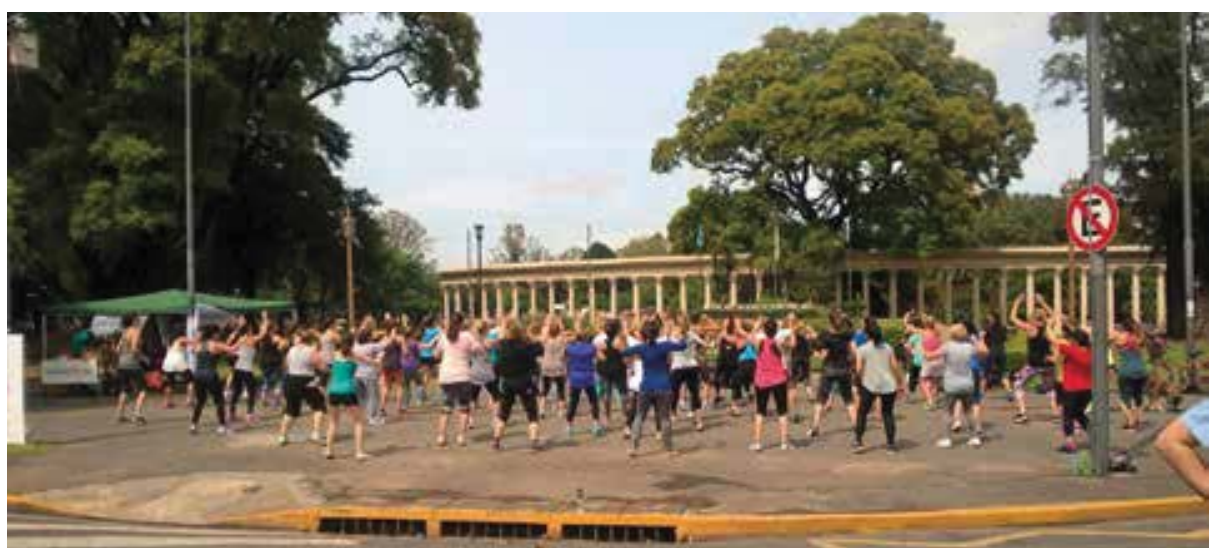

Fuente: captura de los autores.

Figura 3. Estación de ejercicio de piso y elongación

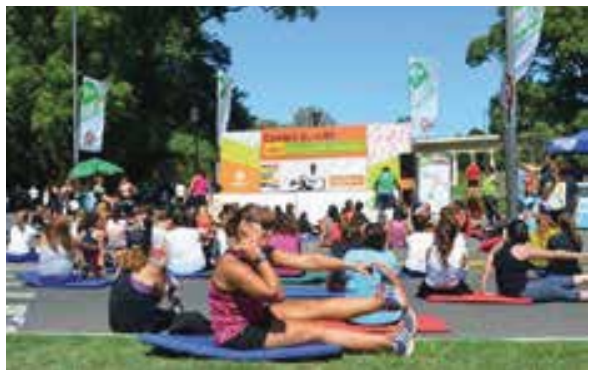

Fuente: Municipalidad de Rosario.

Figura 5. Estación Saludable, frente a los silos del Museo de Arte

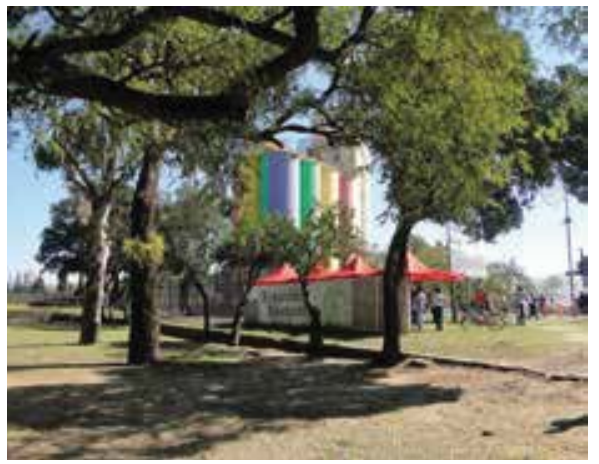

Fuente: captura de los autores.
Figura 4. Recorrido y cartelería sobre Bulevar Oroño

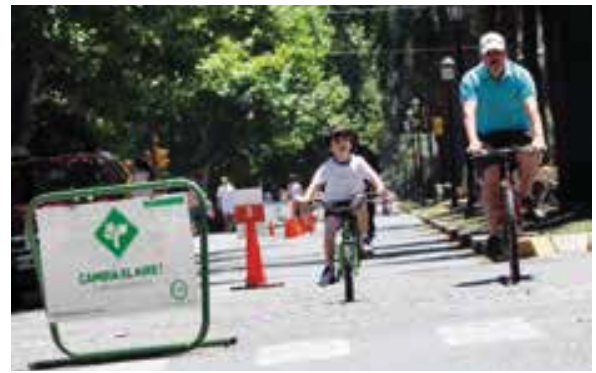

Fuente: Municipalidad de Rosario.

Figura 6. Masajes a un lado Playa de Maniobras del FCCA, al otro Museo Macro Av. Carvallo

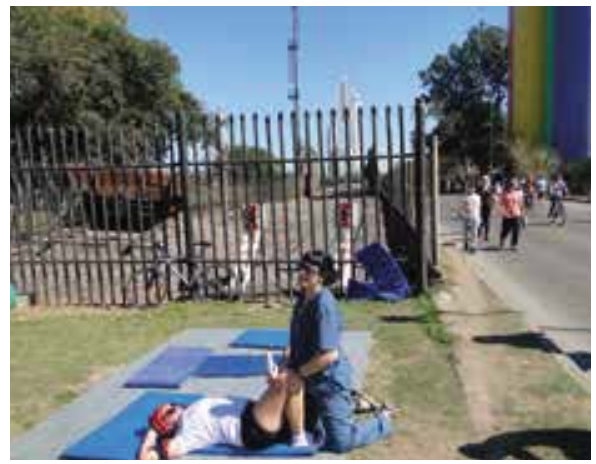

Fuente: captura de los autores. 
Figura 7. Residuos ferroviarios y Vía Recreativa Rumbo Puerto Norte

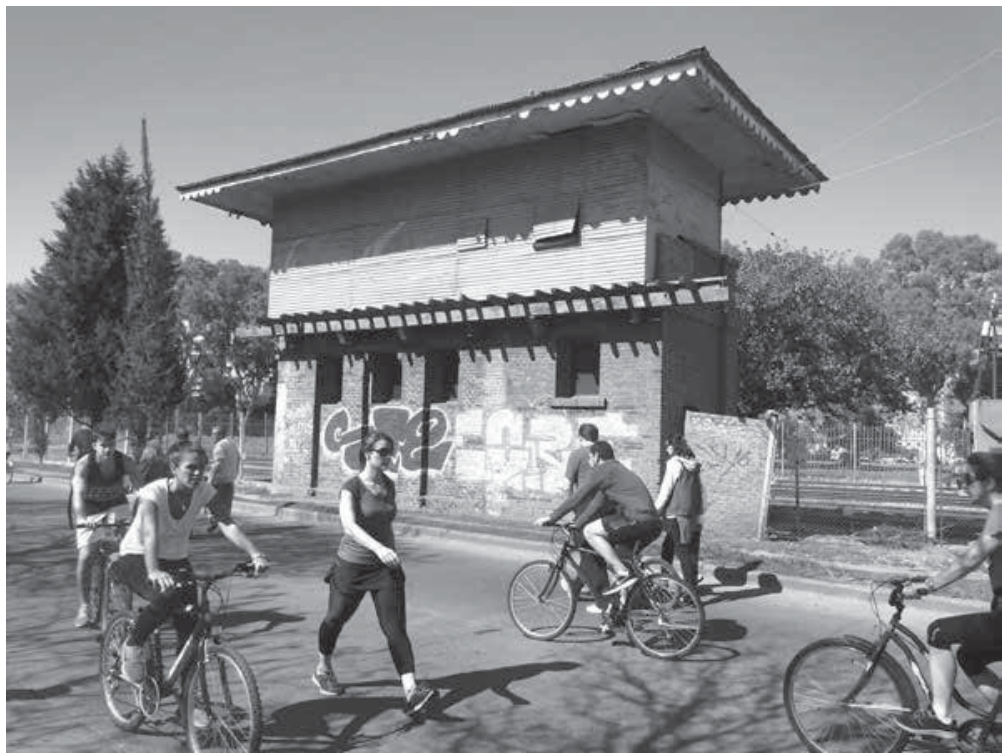

Fuente: captura de los autores.

Figura 8. Torres Countries. Vía Recreativa y Ruinas ferro-portuarias en proceso de "Rehabilitación"

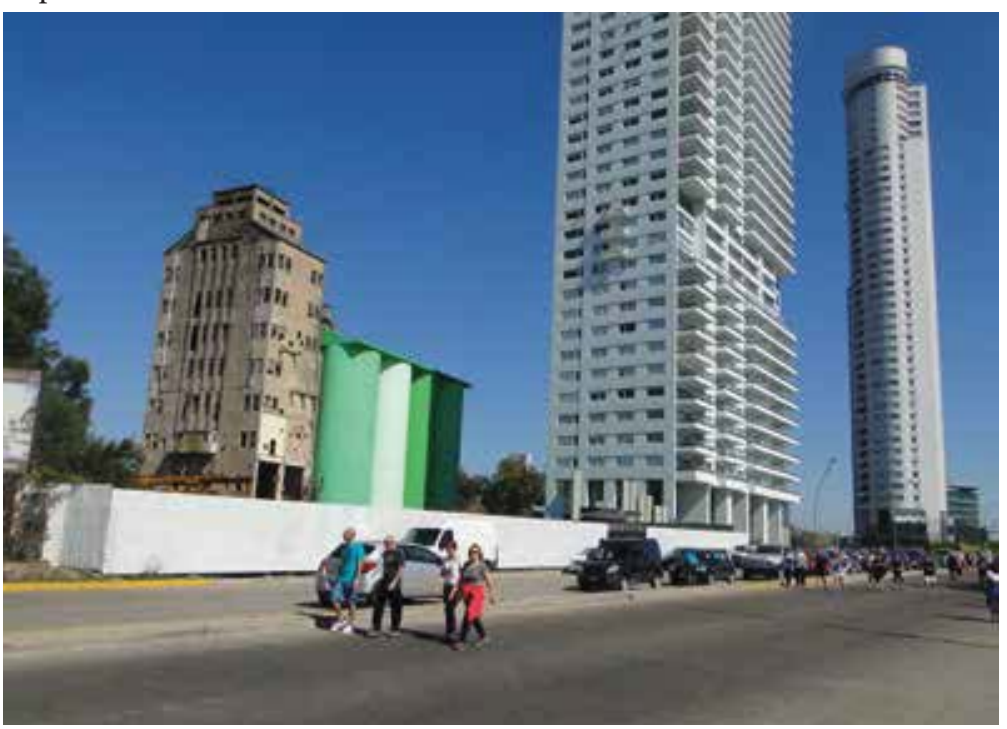

Fuente: captura de los autores. 


\section{CONCLUSIONES}

Alolargo de este trabajo se procuró fusionar dos dimensiones de la existencia social y cultural que, a pesar de su proximidad evidente, han permanecido escindidas durante largo tiempo: el cuerpo y el espacio. Para ello tomamos como guías la antropología del cuerpo, la geografía crítica y el paradigma de la movilidad. Nuestro observatorio empírico lo construimos en la Calle Recreativa de la ciudad de Rosario. En ese espacio público, eventual y específico, todas las mañanas de domingos, se da cita un gran número de cuerpos que se autoimponen la tarea de atravesar ese conducto. Fruto de la relación entre la planificación urbana, el diseño de la ciudad por partes, la producción arquitectónica de la ciudad mercancía y el marketing sobre una Rosario turística y saludable, la Calle Recreativa genera un ambiente donde puede leerse una imagen de dos caras. De un lado, aparecen los cuerpos que recorren el circuito, con sus movimientos pausados, rítmicos, casi como una gran masa de piernas y brazos sincronizados. Del otro, las postales urbanas que vinculan dos escenarios de poder: el bulevar con las antiguas mansiones de la burguesía de comienzos del siglo pasado y la ribera enmarcada en los mega-proyectos urbanos poligonales y torres countries. Esas dos escenas, tan sólo escindibles a fines analíticos, muestran en una sola trayectoria la secreta relación entre cuerpos y espacios. A través de su motricidad, sus vectores de dirección y sus sucesivos posicionamientos, los cuerpos "tejen" al espacio como las estrellas producen a las constelaciones. El espacio social nace del encuentro de la práctica social más simple: el movimiento; con las imágenes, concepciones e imaginarios que lo entornan. La Calle Recreativa configura el ambiente de esos pasos.

Es la galaxia que dicta el orden de los astros que, a su vez, constituyen las sucesivas posiciones de los cuerpos. En definitiva, mediante la iluminación de un tramo peatonal intermitente, ubicado en una ciudad con aspiraciones metropolitanas del Cono Sur, se muestra la dependencia fundamental que el espacio urbano tiene respecto a los cuerpos, las actividades, las relaciones y los imaginarios para existir como un fenómeno social y un medio operable. Precisamente, la Calle Recreativa promueve la imagen de un largo río humano que avanza casien una dirección única, con un ritmo homogéneo, una composición social constante y un objetivo común: un movimiento con niveles variables de compromiso físico-corporal.

A la luz de los resultados del trabajo de registro y participación, podemos afirmar que la Calle Recreativa funciona como un medio en el sentido que atribuyó al término Michel Foucault (2006a). Desde esta perspectiva teórica, el medio es un espacio abierto donde se generan las condiciones de posibilidad para prever series de acontecimientos y conductas aleatorias. Ese medio es sobre todo un soporte a través del cual se induce el deseo de movimiento y se producela movilidad bajo ciertas condiciones sutily estadísticamente gobernadas. 
A través de la organización del medio aparecen una serie de pautas ambientales (control de la dirección, restricción del tráfico, señalización del rumbo mediante vallas, habilitación de circulaciones alternativas y otras) que encausan un deseo de movimiento en una población que busca restablecer su oxigenación tras las semanas de trabajo sedentario o que desea contar con un momento de contacto con el cuerpo fuera de las rutinas del gimnasio u otras actividades físicas. Simultáneamente, ese medio propone un encuentro con las áreas más patrimonializadas (Bulevar Oroño) y gentrificadas de la ciudad (Puerto Norte). Como si se tratara de una narración urbana, el trayecto proyecta sus puntos de luz sobre la ciudad, ilumina lo que desea subrayar y busca identificar la salud del caminante con los espacios de poder, consumo y distinción social. A través de la Calle Recreativa y con la colaboración de sus frecuentadores, el municipio consigue exhibir de manera más o menos duradera sus propias intervenciones urbanas y su relato de una ciudad rehabilitada que triunfa en el contexto global. Al mismo tiempo, a través de una práctica cuasi ritual, este dispositivo urbanístico y cinético procura interiorizar esas figuraciones tanto en el horizonte del deseo como en el imaginario de sus habitantes.

En correlación con la proliferación del narcotráfico en Rosario, agentes de la Gendarmería Nacional han ocupadolajurisdicción dela ciudad como fuerza de apoyo. Su base de operaciones se localiza en el ex predio ferial de la Sociedad Rural de Rosario, en el corazón del Parque Independencia. Los domingos por la mañana, los gendarmes montados en caballos patrullan los alrededores de la Calle Recreativa. En ocasiones se observa la requisa de mochilas de los y las jóvenes que se dedican a la limpieza de coches en el Área del Parque Independencia. De prolongarse esta tendencia, además de los inspectores de tránsito que aseguran el corte del flujo vehicular, el enforcement de la Gendarmería parece estar destinada a resguardar y garantizar las condiciones de circulación en una cierta homogeneidad sociocultural de la Vía Recreativa.

Como bien supo comprender Foucault (2012a y 2012b), toda arquitectura dispone y construye un espacio para la luz, para generar condiciones de visibilidad que buscan ser absolutas. No obstante, De Certeau (1999) acierta en su crítica al panoptismo foucaultiano, porque toda forma de luz produce a su alrededor puntos ciegos, conos de sombra. De hecho, fueron los pasos de los usuarios del Bulevar Oroño los que inspiraron la dirección del circuito y no a la inversa. Asimismo, si se toma la idea decerteauiana de que la acción caminante como relato se vale de las organizaciones espaciales y proyecta una sombra que resalta lo equívoco en ellas (De Certeau, 1980), se observa cómo el recorrido de la Calle Recreativa muestra - de manera lateral y sin proponérselo-lo escasas que son esas zonas renovadas (gentrificadas) y potencialmente renovables de Rosario. De hecho, ni siquiera el recorrido completo se asienta sobre zonas homogéneas y brillantes, los primeros tramos, recostados sobre el sur de la ciudad, no son especialmente atractivos tanto en lo que refiere a su diseño como 
a su equipamiento urbano. Lo que existe alrededor de ese recorrido "turístico" dista mucho de lucir de la misma manera y por lo tanto queda descartado del trayecto, porque previamente ha sido desestimado de la agenda de las intervenciones urbanas del municipio y los capitales privados. Aunque existe una retórica que sostiene cierta expectativa de renovación paulatina y potencial de esas áreas todavía desatendidas del sur y del oeste de la ciudad.

Elgobiernolocal de Rosario se caracteriza por sularga continuidad política enla administración (desde 1989 hasta la actualidad), por una institucionalización fuerte y una sinergia con la universidad pública que, si bien ha producido algunos hechos positivos, también ha redundado en una reducción de la gestión a un asunto técnico y burocrático. A lo largo de este proceso, el municipio estuvo atento a los desarrollos de la población, constantemente trató de captar las energías sociales movilizadas alrededor de ciertos núcleos para homogeneizar su multiplicidad, perimetrar su espacialidad y gestionar su movilidad a través de dispositivos institucionales. Esto resultó notable, por ejemplo, con la institucionalización de las Artes Urbanas y absorción de múltiples artistas callejeros como personal de los nuevos espacios municipales recualificados y destinados al ocio y el esparcimiento (Godoy, 2015). Con la Calle Recreativa, una vez más, podemos observar la consagración de esta operatoria que primero captura y luego potencia (en forma reproductiva, es decir institucionalizada) las energías de los rosarinos que recorrían Oroño para ejercitarse aeróbicamente durante las últimas horas de la tarde y acudían al Parque España con el objetivo de elongar los músculos involucrados en la actividad física.

En este artículo mostramos cómo la movilidad, con sus ritmos y medios diversos, su planteo de un recambio del aire y recuperación de cierta vitalidad, su organización proxémica, sincronizada y unidireccional de una fracción del espacio urbano - precisamente la que es organizada por las fuerzas de la renovación, patrimonialización y puesta en valor-, configura una tecnología de la gubernamentalidad (Foucault, 2006 \& Castro Gómez, 2010). El ocio y la recreación en las sociedades orientadas por el capitalismo avanzado no parecen ser solo una recuperación de las energías o el bienestar perdido en el trabajo, sino una forma de producir, direccionar y modular el deseo de las poblaciones en los momentos en que padecen de cierta orfandad y desorientación en cuanto a la estructuración de sus tiempos, espacios y movimientos; como es el caso de las mañanas de los domingos. Esas guías y esos direccionamientos cancelan las condiciones de posibilidad para la emergencia de la figura literaria compuesta por Paul Auster alrededor de Sachs en Leviatán, en su relación polimórfica y desinteresada con el espacio y los ritmos urbanos y que presta el epígrafe a este artículo.

La Calle Recreativa pauta itinerarios, conductas y deseos, pero su capacidad para instituir, controlar y vigilar son siempre limitadas. Aún con un flujo muy homogéneo, en los márgenes e intersticios de la Calles Recreativa se infiltra lo 
que esa postal de movimiento y paisaje desea reprimir y borrar. Son esos caminantes quellegan de otras calles, quizá menos equipadas urbanísimamente, vestidos deformas menos "adecuadas", pero que configuran la huella de otra ciudad también fragmentada que se extiende de espaldas y por debajo de lo que la Calle recreativa quiere mostrary consagrar como uno delos espacios-momentos-movimientos de una ciudad con centralidades cambiantes y aspiraciones globales.

Enforcement I. Gendarmería Nacional patrulla a Caballo

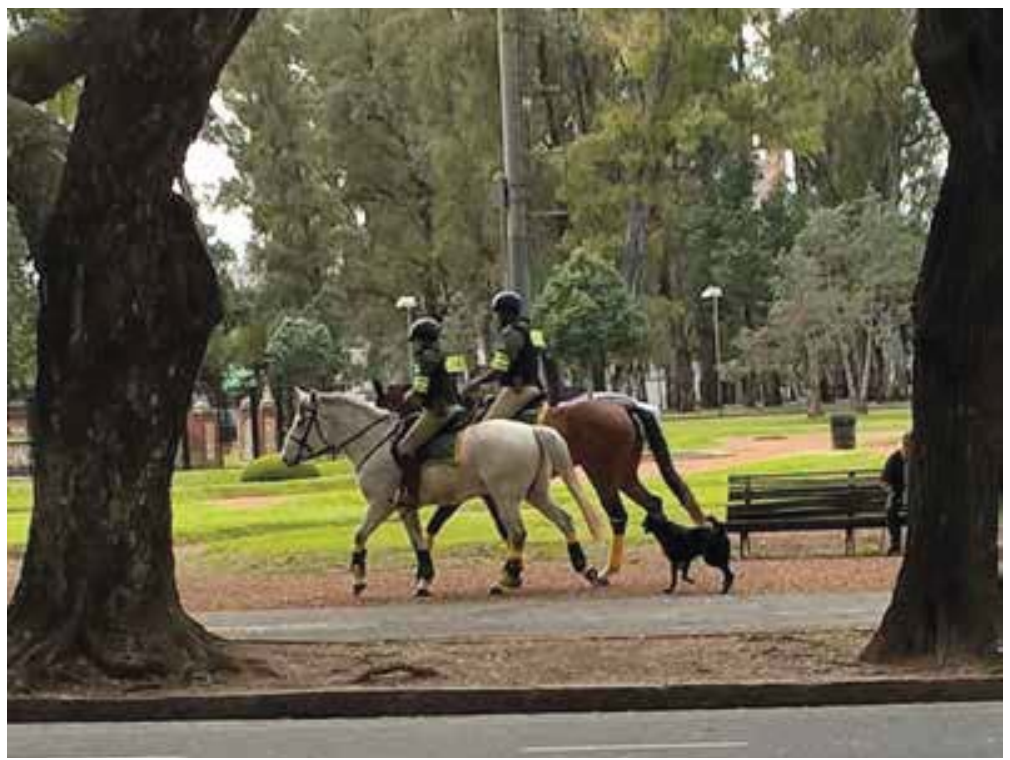

Fuente: captura de los autores.

Enforcement II. Gendarmería Nacional registra mochilas de jóvenes que limpian parabrisas y autos

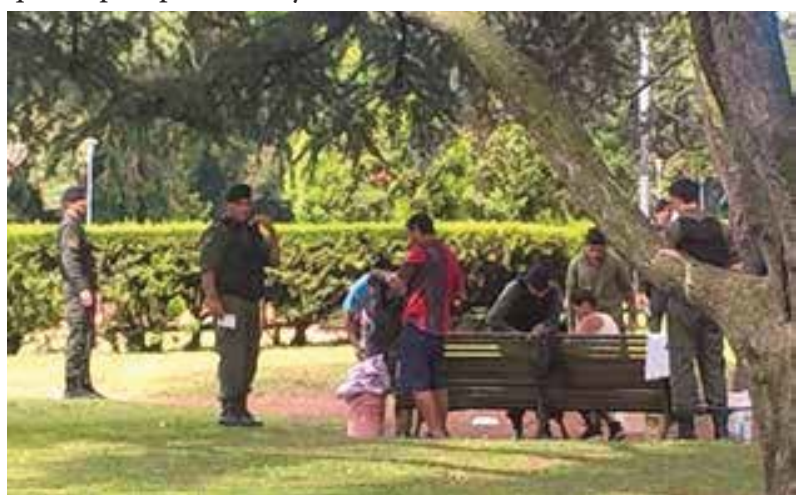

Fuente: captura de los autores. 


\section{REFERENCIAS}

Augé, M. (1998). Los "no lugares". Espacios del anonimato. Una antropología de la sobremodernidad. Barcelona: Gedisa.

Auster, P. (1993). Leviatan. Barcelona: Anagrama.

Bourdieu, P. (1999). Meditaciones pascalianas. Barcelona: Anagrama.

Castro-Gómez, S. (2010). Historia de la gubernamentalidad. Razón de Estado y neoliberalismom en Michel Foucault. Bogota: Siglo del Hombre.

Cosgrove, D. (2004). "Landscape and Landschaft and the Spatial Turn", German Historical Institute Bulletin (35), pp 57-71.

Crampton, J. \& Kryger, J. (2006). An Introduction to Critical Cartography. En ACME: An International E-Journal for Critical Geographies, 4 (1), pp. 11-33.

Csordas, T.(1993). Somatic modes of attention. En Cultural Antrhopology, (8), 2.EE.UU.

Csordas, T. (1999). Embodiment and cultural phenomenology. En Weiss, G. y Honi, F. (eds.) Perspectives on embodiment. New York: Routhledge, pp. 143-162.

De Certeau, M. (1999). La cultura en plural. Buenos Aires: Nueva Visión.

De Certeau, M. (2000, 1980). La invención de lo cotidiano. 1 artes del hacer, México: Universidad Iberoamericana.

Douglas, M. (1988, 1970). Símbolos Naturales. Exploraciones en cosmología. Madrid: Alianza Editorial.

Entwistle, J. (2002). El cuerpo y la moda. Barcelona: Paidós.

Farinelli, F. (2000). "Friedrich Ratzel and the nature of (political) geography". En Political Geography (19), pp. 943-955.

Foucault, M. (2006a). El nacimiento de la biopolítica. Buenos Aires: Fondo de Cultura Económica.

Foucault, M. (2006b). Seguridad, territorio, población. Buenos Aires: Fondo de Cultura Económica.

Foucault, M. (2010). Espacios diferentes (heterotopías). En El cuerpo Utópico. Las heterotopías. Buenos Aires: Nueva Visión, pp. 63-81.

Foucault, M. (2012a). Historia de la locura en la época clásica. Buenos Aires: Fondo de Cultura Económica.

Foucault, M. (2012b). Vigilar y castigar. Madrid: Siglo XXI.

Gregory, D. (1984). Ideología, ciencia y geografía humana. Barcelona: Oikos-Tau.

Gregory, D. (1996). Geographical imaginations. Oxford, Cambridge, Massachusetts: Blackwell Publishers. 
Godoy, S. (2015). Otras ciudades posibles. Itinerarios artísticos y resignificaciones del espacio público. Rosario 1994-2002. En Prácticas de Oficio (16), pp. 1-17.

Goffman, E. (1997). La presentación de la persona en la vida cotidiana. Buenos Aires: Amorrortu.

Hall, E. T. (1987). La dimensión oculta. Madrid: Siglo XXI.

Hannam, K., Sheller, M. \& Urry, J. (2006). Mobilities, immobilities and moorings. En Mobilities, 1(1), pp. 1-22

Harvey, D. (1990). La condición de la posmodernidad. Investigaciones sobre el cambio cultural. Buenos Aires: Amorrortu.

Harvey, D. (2007). Espacios de Esperanza. Akal: Madrid.

Harvey, D. (2008). Ciudades rebeldes. Del derecho a la ciudad a la revolución urbana. Madrid: Akal.

Hespanha, A. M. (1989). Vísperas del Leviatán. Instituciones y poder político (Portugal, siglo XVII). Madrid: Taurus.

Lacoste, Y. (1977). La geografía: un arma para la guerra. Barcelona: Anagrama.

Le Breton, D. (1995). Antropología del cuerpo ymodernidad. Buenos Aires: Nueva Visión.

Leenhardt, M. (1961). Do Kamo. Buenos Aires: Eudeba.

Low, S. (2003a). Embodied Space(s): Anthropological Theories of Body, Space, and Culture. En Space and Culture, (6). 9, pp.9-18.

Low, S. (2003b). Behind the Gates: Life, Security and the Pursuit of Happiness in Fortress America. Routledge: New York \& London.

Merleau-Ponty, M.(1993). Fenomenología delapercepción. Barcelona: Planeta-Agostini.

Rabotnikof, N. (1997). El espacio público y la democracia moderna. México: Instituto Federal Electoral.

Ribeiro, G. (2015). La genèse de la géohistoire chez Fernand Braudel: un chapitre de l'histoire dela pensé géographique, En Annales de géographie (4) 686, pp. 329-346.

Roldán, D. P. (2010). “Discursos alrededor del cuerpo, la máquina, la energía y la fatiga: hibridaciones culturales en la Argentina fin de sieclè", en Revista História, Ciência eSaúde-Manguinhos (17), 3, pp. 643-661.

Sheets-Johnstone, M. (2009) The corporeal turn. Charlottesvile, EE.UU.: Imprint Academic.

Smith, N. (1990). Uneven development. Nature, Capital and Production of Space. Cambridge: Blackwell. 
Smith, N. (2013). La nueva frontera urbana. Madrid: Traficantes de Sueños.

Soja, E. (1996). Third space: Journeys to Los Angeles and Other Real-and-Imagined Place. Oxford: Blackwell.

Soja, E. (2000). Postmetrópolis. Estudios Críticos sobrelas ciudades y las regiones. Madrid: Traficantes de Sueños.

Soja, E. (2010). Tercer Espacio. El alcance de la imaginación geográfica. En Albet, Abel y Benach, Núria. (Eds.). (2010). Edward W. Soja. La perspectiva posmoderna de un geógrafo radical. Barcelona: Icaria, pp.181-209.

Turner, V. (1989). El proceso ritual. Madrid: Taurus.

Turner, B. (1989). El cuerpo y la sociedad. México D.F.: Fondo de Cultura Económica.

Urry, J. (2004). La mirada del turista. Lima: Universidad San Martín de Porres.

Vera, P. (2015a). Ciudad saludable, ciudad turística. Espacialización de imaginarios y prácticas urbanas (Rosario, Argentina). En ROTUR, Revista de Ocio y Turismo, 10 , pp. 43-58.

Vera, P.(2015b). Estrategias patrimoniales y turísticas: su incidencia en la configuración urbana. El caso Rosario, Argentina. En Territorios, 33, Bogotá, pp. 83-102.

Wacquant, L. (2004). Entre las cuerdas. Cuadernos de un aprendiz de boxeador, Madrid: Alianza.

Wallersten, I. (2006). Análisis de sistema-mundo. Una introducción. México: Siglo XXI.

\section{IDENTIFICACIÓN DE LOS AUTORES}

Diego Roldán es Doctor en Humanidades y Artes. Investigador Adjunto del CONICET, Argentina. Profesor de la cátedra de Espacio y Sociedad en la Universidad Nacional de Rosario (UNR). Director del Centro de Estudios Culturales Urbanos (CECUR) de la UNR. Sus investigaciones se focalizan en los procesos urbanos de reconfiguración neoliberal de los espacios urbanos contemporáneos.

Sebastián Godoy es Profesor de Historia. Becario de Formación Doctoral del CONICET, Argentina. Profesor de la cátedra de Espacio y Sociedad en la UNR. Investigador del CECUR. Sus investigaciones se concentran en los procesos de apropiación del espacio desde las artes urbanas, el empleo de los cuerpos y la ocupación de espacios residuales en el proceso de creación de paisajes contraculturales.

\section{REGISTRO BIBLIOGRÁFICO}

Godoy, S. y Roldán, D. (2017). Cuerpos, movilidades y espacios. La calle recreativa de Rosario, Argentina. InMediaciones de la Comunicación, 12(1), 129-153. 